\title{
Mortality from lung cancer and other diseases related to smoking among fishermen in north east Italy
}

Giuseppe Mastrangelo, Emanuele Malusa, Corrado Veronese, Anna Zucchero, Vita Marzia, Angelo Boscolo Bariga

\begin{abstract}
Objectives-To study the mortality of fishermen. This was suggested by a cluster of cases of lung cancer in Chioggia, a large fishing harbour in the Veneto. The aim was to weight occupation against smoking with respect to risk of lung cancer. Methods-7530 fishermen registered in the 1971-86 port authority registers of Chioggia and Venice were followed up for mortality from 1971 to 1989 . Of 475 causes of death, 460 were traced. Standardised mortality ratio (SMR) was calculated with the regional population as a reference. A nested case-control study was carried out in Chioggia decedents only by interviewing next of kin. Complete data were obtained in $172 \mathbf{( 7 0 \%}$ response). Cases (lung cancer deaths) and controls (other causes of death) were compared for smoking and occupation, as a group of non-fishermen was available in the cohort. Logistic regression analysis was used to adjust for confounding factors.
\end{abstract}

Results-SMRs were high for lung cancer but low for other diseases related to smoking: circulatory and respiratory disease, tumours of the mouth, pharynx, oesophagus, and bladder. Likewise, SMRs were high for liver cancer but low for other diseases related to alcohol: digestive and circulatory disease, buccal, pharyngeal, and oesophageal tumours. In the case-control study, the risk of lung cancer was found to be related to smoking, and there was no interaction between occupation and smoking. When adjusted for age and smoking, the occupational indicators had no influence on the risk of mortality from lung cancer.

Conclusions-Among fishermen in north east Italy the greatest health hazard is lung cancer, and the factor involved in this risk is smoking, not occupation. Smoking, however, was linked with long hours at sea in another study.

(Occup Environ Med 1995;52:150-153)

Keywords: fishermen; smoking; mortality

An extensive evaluation of the mortality in deep sea fishermen has been made in only three studies: on British ${ }^{1}$ and Swedish Baltic Sea fishermen, ${ }^{2}$ and on Canadian commercial fishermen. ${ }^{3}$ It has been found that fishermen tend to be heavy smokers, ${ }^{12}$ but to our know- ledge no studies have weighed the occupation itself against smoking. The paucity of information points to the need for more consistent and comprehensive data collection that would allow a clear identification of risk factors linked to the occupation or to the particular lifestyle of these workers.

Chioggia (53 570 inhabitants in 1981) is one of the largest fishing harbours in Italy, where fishermen make up about $11 \%$ of the male workforce. The mortality from lung tumours in men who reside in the health district of Chioggia is the highest of all the health districts in the whole of Italy. ${ }^{4}$ We therefore decided to carry out a mortality study among these fishermen. To make a more reliable risk assessment, however, the study was extended to all deep sea fishermen on the north east coast (Veneto region) of Italy.

\section{Materials and methods}

In Italy all deep sea fishermen must be entered (Act No 963 of 1965) in the port authority registers. We therefore made a cohort study for which the subjects were traced in the 1971 to 1986 registers of the Port Authorities of Chioggia (4870) and Venice (2660), the only two port authorities in the Veneto. The vital status of the 7530 cohort members was ascertained through the registry offices of the last municipality of residence in the observation period ( 1 January 1971 to 31 December 1989). Death certificates were obtained from the registry office of the locality where the death occurred in 460 of the 475 deaths. The cause of death was coded according to the revision of the International Classification of Diseases (ICD) effective at the time of death. The personyears were calculated by a computer program from the date of registration as date of entry in the cohort to death or the end of follow up as the exit date. The expected mortality was the product of the person-years and the Veneto mortality by cause, taking into account age (five year groups), sex, changes in ICD codes, and calendar periods $(1970-2,1973-5$, 1976-8, 1979-81, 1982-4, 1985-6, 1987-9). Due to incomplete regional data, mortality figures for the period 1972 to 1986 were also applied during the period 1987 to 1989 . The standardised mortality ratio (SMR) was the ratio between observed and expected deaths. Two tailed $95 \%$ confidence intervals (95\% CIs) for the SMR were calculated on the assumption of a Poisson distribution of observed cases.

Facciolati 71, 3512

Accepted 28 October 1994 
Table 1 Distribution of person-years by age and calendar year of the Veneto fishermen at entry to the study

\begin{tabular}{lrrrr}
\hline & \multicolumn{2}{l}{ Age $(y)$} & & \\
\cline { 2 - 5 } Calendar year & $<24$ & $25-44$ & $45-64$ & Total \\
\hline $1971-5$ & 6789 & 28804 & 17027 & 52620 \\
$1976-80$ & 9152 & 6317 & 3457 & 18926 \\
$1981-6$ & 9081 & 3037 & 912 & 13030 \\
Total & 25022 & 38158 & 21396 & 84576 \\
\hline
\end{tabular}

Table 2 Mortality by cause in the cohort of Veneto fishermen

\begin{tabular}{|c|c|c|c|c|}
\hline Cause of death & $O$ & $E$ & $S M R$ & $95 \% C I$ \\
\hline All causes & 460 & 430.9 & 1.07 & $(0.92-1 \cdot 10)$ \\
\hline Infective & 1 & $3 \cdot 7$ & $0 \cdot 27$ & $(0.01-1.50)$ \\
\hline Tumours: & 230 & 150.9 & 1.53 & $(1.33-1.73)$ \\
\hline Buccal or pharynx & 6 & $10 \cdot 2$ & 0.59 & $(0 \cdot 22-1 \cdot 23)$ \\
\hline Oesophagus & 6 & 7.5 & 0.82 & $(0.30-1.79)$ \\
\hline Stomach & 13 & $10 \cdot 4$ & $1 \cdot 25$ & $(0.67-2 \cdot 14)$ \\
\hline Colon and rectum & 14 & $9 \cdot 6$ & 1.45 & $(0 \cdot 79-2 \cdot 44)$ \\
\hline Liver, biliary & 17 & $7 \cdot 4$ & $2 \cdot 31$ & $(1 \cdot 35-3 \cdot 70)$ \\
\hline Pancreas & 6 & $5 \cdot 6$ & 1.07 & $(0 \cdot 39-2 \cdot 33)$ \\
\hline Other digestive & 1 & 1.9 & 0.53 & $(0.01-2.95)$ \\
\hline Larynx & 12 & $7 \cdot 2$ & 1.66 & $(0.86-2.91)$ \\
\hline Lung & 105 & $52 \cdot 8$ & 1.99 & $(1.63-2.41)$ \\
\hline Other respiratory & 2 & $1 \cdot 7$ & 0.58 & $(0.07-2.09)$ \\
\hline Bone & 3 & $1 \cdot 0$ & $2 \cdot 89$ & $(0 \cdot 60-8 \cdot 44)$ \\
\hline Connective tissue & 1 & 0.3 & 2.99 & $(0.08-16 \cdot 7)$ \\
\hline Melanoma & 2 & $1 \cdot 5$ & 1.33 & $(0 \cdot 16-4 \cdot 80)$ \\
\hline Other skin & 1 & 0.5 & $2 \cdot 22$ & $(0 \cdot 06-12 \cdot 4)$ \\
\hline Prostate & 4 & $3 \cdot 1$ & 1.29 & $(0 \cdot 35-3 \cdot 30)$ \\
\hline Bladder & 3 & 6.9 & 0.51 & $(0 \cdot 11-1 \cdot 49)$ \\
\hline Kidney & 5 & $3 \cdot 3$ & 1.52 & $(0.49-3.54)$ \\
\hline Brain & 5 & $3 \cdot 6$ & $1 \cdot 38$ & $(0 \cdot 45-3 \cdot 22)$ \\
\hline Thyroid gland & 1 & $0 \cdot 4$ & 2.54 & $(0 \cdot 06-14 \cdot 2)$ \\
\hline Lymphosarcoma & 2 & $2 \cdot 5$ & 0.79 & $(0 \cdot 10-2 \cdot 85)$ \\
\hline Hodgkin's & 1 & 1.5 & 0.65 & $(0.02-3 \cdot 62)$ \\
\hline Myeloma & 3 & $1 \cdot 2$ & $2 \cdot 52$ & $(0 \cdot 52-7 \cdot 36)$ \\
\hline All leukaemias & 1 & $3 \cdot 2$ & 0.31 & $(0.01-1 \cdot 73)$ \\
\hline Other and unspecific & 16 & $7 \cdot 6$ & $2 \cdot 11$ & $(1 \cdot 21-3 \cdot 42)$ \\
\hline Endocrine & 3 & $5 \cdot 8$ & 0.51 & $(0 \cdot 11-1 \cdot 49)$ \\
\hline Blood & 1 & 0.8 & $1 \cdot 24$ & $(0.03-6.91)$ \\
\hline Mental & 1 & $3 \cdot 0$ & 0.34 & $(0.01-1 \cdot 89)$ \\
\hline Nervous system & 2 & $6 \cdot 0$ & 0.33 & $(0 \cdot 04-1 \cdot 19)$ \\
\hline Circulatory system & 107 & $122 \cdot 4$ & 0.87 & $(0 \cdot 72-1 \cdot 06)$ \\
\hline Respiratory system & 10 & $16 \cdot 7$ & 0.60 & $(0 \cdot 29-1 \cdot 10)$ \\
\hline Digestive system & 40 & $47 \cdot 4$ & 0.84 & $(0 \cdot 60-1 \cdot 14)$ \\
\hline Genitourinary & 2 & $3 \cdot 3$ & 0.60 & $(0 \cdot 07-2 \cdot 17)$ \\
\hline Congenital & 2 & $1 \cdot 0$ & $2 \cdot 07$ & $(0 \cdot 25-7 \cdot 47)$ \\
\hline Ill defined symptoms & 11 & $3 \cdot 4$ & $3 \cdot 27$ & $(1.63-5.83)$ \\
\hline Accidents & 50 & $66 \cdot 2$ & 0.75 & $(0.56-0.99)$ \\
\hline
\end{tabular}

$\mathrm{O}=$ observed; $\mathrm{E}=$ expected.
One hundred and eighty nine questionnaires were completed, but full information was obtained for only 172 subjects $(70 \%$ of the total). For another two, the cause of death was unknown. Notwithstanding all the efforts made, $31(12.6 \%)$ of the subjects were not traced, and $25(10 \cdot 1 \%)$ refused to cooperate. The subjects who had died from lung tumours were considered to be cases, and those who had died from other causes were considered to be controls. Then age (always expressed as an interval variable), smoking, and occupation were used in a stepwise logistic regression to calculate the relative risk (RR) of lung cancer from each variable, taking into account the effects of the other variables. ${ }^{5}$

\section{Results}

Table 1 shows the distribution of the personyears in the cohort of the registered Veneto fishermen at entry to the study. Table 2 shows the observed and expected mortality in this cohort, and the SMR for each cause of death. The considerable increase in lung cancer (SMR $=1.99,105$ observed) is accompanied by an unexpected reduction in other diseases related to smoking: tumours of the mouth, pharynx, oesophagus, and bladder, as well as circulatory and respiratory diseases. Pancreas, kidney, and larynx tumours, which are also related to smoking, were only slightly increased. Likewise, the significant excess of liver cancer ( $S M R=2.31,17$ observed) is contrasted with the reduction in other causes of death related to alcohol: tumours of the mouth, pharynx, and oesophagus, digestive diseases, and external causes. On the other hand, there were two deaths certified as cancer of ill defined sites of the respiratory system (neither was mesothelioma), and an excess mortality from myeloma and from thyroid gland tumour, although this was not significant. Out of 50 external causes of death, there were 14 cases of accidents at sea (water transport accidents or drowning, not shown in table 2), which give an absolute rate of $16 \cdot 6 / 10^{5}$ person-years.

Table 3 shows the distribution of the 172 subjects in the case-control study, according to the dichotomous variables-smoking and occupation as fishermen. In table 3, former smokers with $\leqslant 15$ years of abstinence from smoking were included as current smokers; those with $>15$ years were grouped with the life-long non-smokers. Table 3 also shows the RRs for one factor, adjusted for age and for the effect of the other factor by the logistic regression. These show that smoking carries the increased risk of lung cancer. Smoking and occupation are used as dichotomous variables in this analysis. Their interaction (smoking $\times$ occupation), which was further introduced into the logistic regression, was not significant and did not change the previous RR estimates.

Table 4 shows the RR of lung cancer, estimated according to three models by means of logistic regression. In model 1 , smoking duration and age are significant predictors of the

and age stopped, if pertinent). naires were posted, and interviewees who did not reply were searched for at their homes. 
Table 4 Three inodels of logistic regression analysis

\begin{tabular}{|c|c|c|c|c|c|}
\hline Variables & $F$ & $D F$ & $D F$ & $R R$ & $(95 \% C I)$ \\
\hline \multicolumn{6}{|l|}{ Model 1: } \\
\hline Smoking duration (y) & $9 \cdot 08^{\star \star}$ & 1 & 142 & $1 \cdot 15$ & $(1 \cdot 04-1 \cdot 29)$ \\
\hline Age $(y)$ & $4 \cdot 71^{\star}$ & 1 & 142 & 0.90 & $(0 \cdot 81-1 \cdot 00)$ \\
\hline Work duration (y) & 1.73 & 1 & 142 & - & - \\
\hline Constant & $0 \cdot 25$ & 1 & 142 & - & - \\
\hline \multicolumn{6}{|l|}{ Model 2: } \\
\hline Time since start of smoking $(y)$ & $6 \cdot 07^{\star}$ & 1 & 156 & $1 \cdot 16$ & $(1 \cdot 02-1 \cdot 33)$ \\
\hline Age (y) & $3 \cdot 89^{\star}$ & 1 & 156 & $0 \cdot 88$ & $(0.77-1.01)$ \\
\hline Time since start of work $(y)$ & 0.95 & 1 & 156 & - & - \\
\hline Constant & 0.00 & 1 & 156 & - & - \\
\hline \multicolumn{6}{|l|}{ Model 3: } \\
\hline Age (y) & 0.03 & 1 & 87 & - & - \\
\hline Time since end of smoking & 0.66 & i & 87 & - & - \\
\hline Time since end of work & $0 \cdot 61$ & 1 & 87 & - & - \\
\hline Constant & $12 \cdot 86^{\star \star}$ & 1 & 87 & 0.45 & $(0 \cdot 28-0 \cdot 69)$ \\
\hline
\end{tabular}

$\star \mathrm{P}<0.05 ;{ }^{\star} \star \mathrm{P}<0.01$

$\mathrm{F}=$ statistics to enter or remove variables; $\mathrm{DF}=$ degrees of freedom; $95 \% \mathrm{CI}=95 \% \mathrm{CI}$ of $\mathrm{RR}$.

Table 5 Prevlences of smoking in decedents and active fishermen in Chioggia, and in a sample of men from the general Veneto population

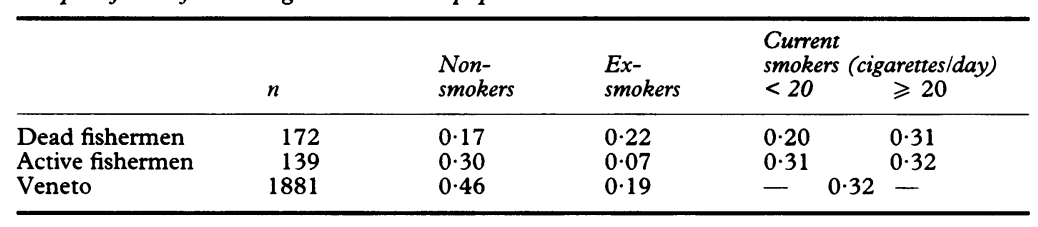

risk of lung cancer; work duration and the constant are not. For non-significant variables, the analysis does not provide an RR estimate. The product of the significant RRs of lung cancer is the "net" excess risk of lung cancer, due, for example, to a one year increase in the duration of smoking, taking into account a one year variation in age. In model 2, the period since the start of smoking to death significantly increased the risk of lung cancer; the influence of age was of borderline significance. In model 3, age, stopping smoking, or the end of work had no influence on the risk of death from lung cancer. In all the models, interval variables were used. The total degrees of freedom in table 4 vary because the data required were not always forthcoming.

Table 5 shows data on smoking in decedents in the case-control study, active Chioggia fishermen in a cross sectional study made by us in $1986-7,{ }^{6}$ and an ISTAT sample of the general male population in the Veneto in a study made in $1986-7 .^{7}$ Data obtained by interviews of next of kin are comparable with those from direct interview and they show that fishermen smoke much more than the general population of the Veneto. The percentage of ex-smokers in the group of active fishermen was $7 \%$, and in decedents it was $22 \%$. In the decedents the mean (SD) period since the end of smoking was $7 \cdot 6(7 \cdot 7)$ years and the mean age at which they stopped smoking was $51.5(11 \cdot 6)$.

\section{Discussion}

We applied to port authorities for their lists as they were the most complete: fishermen who fail to register with them are liable to prosecution (Law No 963 of 1965). Yet the port authorities do not require notification of termination of occupation because of death, retirement, or change of work. So subjects registered are never cancelled. This explains why 47 of 172 subjects $(27 \cdot 3 \%)$ had never been deep sea fishermen although they appeared in the list of the port authority (table 3 ). The rate of $16 \cdot 6 / 10^{5}$ deaths from accidents at sea in 1972-89 was lower than the 49.5 observed in Swedish fishermen in 1944-87, the 45.8 reported in Canadian fishermen in $1975-83,{ }^{8}$ the 260 in New Zealand fishermen in $1975-84,{ }^{9}$ and the 140 to 320 in British fishermen in 1958-67..$^{1}$ The lower risk is partly due to a bias from the presence of nonfishermen in our cohort, and also to the fact that our subjects fish at a lower latitude and nearer the shore.

In fishermen, unlike in commercial seamen, ${ }^{10-11}$ no cases of mesothelioma, a "sentinel health event" of asbestos exposure, were found. Unlike exposure to asbestos and smoking, ${ }^{12}$ work as fishermen and smoking had no multiplicative effect on the risk of lung cancer. It is therefore reasonable to assume that any exposure to asbestos in this category is not involved in excess mortality from lung cancer. With the case-control approach, which is the most accurate method available for controlling the influence of smoking, ${ }^{13}$ we showed that the increased risk of lung cancer found in fishermen was probably due to their smoking habit, not to their occupation (tables 3-4). In a cross sectional study on Chioggia fishermen, a significant association was found between cigarettes a day and workshift hours. ${ }^{6}$ Smoking therefore reflects an important occupational feature of these subjects.

Despite the high tobacco consumption, ${ }^{1.2}$ a decrease in mortality from cardiovascular disease was found by Hagmar et al in Swedish Baltic Sea fishermen, ${ }^{2}$ by Neutel in Canadian east coast fishermen, ${ }^{3}$ and also by us in this study. Hagmar et al suggested the reduction might be due to high fish consumption, with an increased uptake of $n-3$ polyunsaturated fatty acids and selenium. ${ }^{2}$ The fish consumption hypothesis, however, explains neither the reduction in mortality from respiratory disease found among our subjects and Canadian fishermen, ${ }^{3}$ nor the decrease in mortality from several cancers related to smoking, found in the study of Hagmar $e t \mathrm{al}^{2}$ and in our cohort. Among decedents in our case-control study, $22 \%$ had stopped smoking. The effects of stopping smoking have not been well documented. It is well known that mortality from both cardiovascular disease and cancer in subjects who never smoked is similar to that of former smokers after 10 to 14 years from the end of smoking. ${ }^{14}$ In the first years after stopping smoking, however, various diseases may have different temporal patterns of decreasing mortality. Circulatory disease, for example, may be the most readily reversible adverse effect of smoking: in one study, a $24 \%$ reduction in risk of mortality for cardiovascular disease was found in former smokers within two years of stopping smoking. ${ }^{14}$ On the other hand, according to a large study, age when smoking stopped has a greater impact on subsequent risk of lung cancer than years since stopping. ${ }^{15}$ 
Possibly, old age at cessation, few years of abstinence, and heavy past consumption of tobacco do not elicit a decrease in mortality from lung cancer.

An excess of liver cancer was also found in our cohort. It is known that high alcohol consumption increases the risk of liver cancer, ${ }^{10}$ and fishermen tend to be heavy drinkers. ${ }^{17}$ Gathering information on the smoking habits of decedents is difficult, but it may be an even more delicate matter obtaining information on alcohol consumption. We therefore decided to avoid asking for information from next of kin about their deceased relatives' alcohol consumption.

\section{Conclusions}

Lung and liver cancer are the most frequent health hazards among Veneto deep sea fishermen. Smoking, not occupation, is the main risk factor in the mortality from lung cancer. Another study, however, suggested that cigarette smoking increased with workshift hours at sea. A high percentage of decedents were ex-smokers, and probably the low mortality from diseases related to smoking other than lung cancer may be due to the early effect of stopping smoking.

The study was supported by a grant from the "Centro di Cancerogenesi Ambientale".
1 Schilling RSF. Hazards of deep-sea fishing. $\mathrm{Br} \mathcal{F}$ Ind Med $1971 ; 28: 27-35$

2 Hagmar L, Linden K, Nilsson A, Norrving B, Akesson B, Schutz A, Moller T. Cancer incidence and mortality among Swedish Baltic Sea fishermen. Scand $\mathcal{f}$ Work Environ Health 1992;18:217-24.

3 Neutel CI. Mortality in fishermen: an unusual age distribution. Brf Ind Med 1990;47:528-32.

4 Mastrangelo G, Rizzi P, Casson FF. Mortalità per causa nel Comune di Chioggia confrontata con quella della Provincia di Venezia. Atti del Convegno "Pescatori Salute". Chioggia: Veneta Editrice, 1989.

5 BMDP Statistical Software Manual. Berkeley: University of California Press, 1992

6 Casson FF, Mastrangelo G, Saia B. Lo stato di salute dei pescatori d'alto mare di Chioggia. Atti del Convegno "Pescatori e Salute". Chioggia: 1989.

7 Istituto Nazionale di Statistica. Indagine statistica sulle condizioni di salute della popolazione e sul ricorso ai servizi sanitari (novembre 1986-aprile 1987). ISTAT Note e Relazioni 1991;2:182.

8 Hasselback P, Neutel CI. Risk for commercial fishing deaths in Canadian Atlantic provinces. $\mathrm{Br} \mathcal{F}$ Ind Med 1990;47:498-501.

9 Norris AE, Cryer PC. Work related injury in New Zealand commercial fishermen. $\mathrm{Br} \mathcal{F}$ Ind Med 1990;47:726-32.

10 Greenberg M. Cancer mortality in merchant seamen. Ann NY Acad Sci 1991;643:321-32.

11 Rapiti E, Turi E, Forastiere F, Borgia P, Comba P, Perucci CA, Axelson O. A mortality cohort study of seamen in Italy. Am f Ind Med 1992;21:863-72.

12 Hammond EC, Selikoff IJ, Seidman H. Asbestos exposure, cigarette smoking and death rates. Ann NY Acad sure, cigarette smokin

13 Steenland K, Beaumont J, Halperin W. Methods of control for smoking in occupational cohort mortality studies. Scand 7 Work Environ Health 1984;10:143 9

14 Kawachi I, Colditz GA, Stampfer MJ, Willet WC, Manson $\mathrm{JE}$, Rosner B, et al. Smoking cessation in relation to total mortality rates in women. A prospective cohort study. Ann Intern Med 1993;119:992-1000.

15 Halpern MT, Gillespie BW, Warner KE. Patterns of absolute risk of lung cancer mortality in former smokers. f Nat Cancer Inst 1993;85:457-64.

16 Alcohol drinking. IARC Monogr Eval Carcinog Risks Hum 1988;44:207-15.

17 Brix K, Hunter D, Colley P. Incidence of treated alcoholism in north-east Scotland, and Shetland fishermen, 1966-70. Br F Ind Med 1982;39:11-7.

\section{Instructions to authors}

Three copies of all submissions should be sent to: The Editor, Occupational and Environmental Medicine, BMJ Publishing Group, BMA House, Tavistock Square, London WC1H 9JR, UK. All authors should sign the covering letter as evidence of consent to publication. Papers reporting results of studies on human subjects must be accompanied by a statement that the subjects gave written, informed consent and by evidence of approval from the appropriate ethics committee. These papers should conform to the principles outlined in the Declaration of Helsinki (BMF 1964; ii:177).
If requested, authors shall produce the data on which the manuscript is based, for examination by the Editor.

Authors are asked to submit with their manuscript the names and addresses of three people who they consider would be suitable independent reviewers. They will not necessarily be approached to review the paper.

Papers should include a structured abstract of not more than 300 words, under headings of Objectives, Methods, Results, and Conclusions. Please include up to three keywords or key terms to assist with indexing. 